\title{
The effects of cyclones, tsunami and earthquakes on built environments and strategies for reduced damage
}

\author{
R.S. Mallawaarachchi* and C. Jayasinghe \\ Department of Civil Engineering, University of Moratuwa, Katubedda.
}

\begin{abstract}
There is a general belief that Sri Lanka is in a disaster free zone. However, frequent cyclone warnings and earthquake tremors over the past few decades and the December 2004 Tsunami show that this belief may no longer be valid for Sri Lanka. The Tsunami of $26^{\text {th }}$ December 2004, which devastated a $800 \mathrm{~km}$ stretch of costal area of Sri Lanka killed more than 36,000 unwary people and displaced more than 800,000 . It was the worst ever disaster in the history of Sri Lanka. Due to inadequate attention paid to these events in construction practice, the damages caused are enormous both to human life and to the built environment. There is no guarantee that this kind of natural disaster will not happen again. They could repeat in the future, may be with lower magnitudes or intensity. This indicates that some kind of disaster preparedness is of great importance today. This paper deals with few natural disasters which could affect the built environment, and suggests some simple and useful guidelines to improve the disaster resistance of low rise buildings.
\end{abstract}

Keywords: Built environments, disaster resistance, natural disasters

\section{INTRODUCTION}

Damage to built environments from natural disasters are unpredictable and unavoidable at most of the times. Natural disasters occur when the earth releases its concentrated energy gained from various energy sources. It can release the energy in the form of earthquakes, cyclones, tsunami, volcanic eruptions, land slides, floods, wild forest fires, etc., and cause much damage to both human lives and built environments.

Basically, there are four types of energy sources which energize the whole earth system. They are the earth's internal heat, sun, gravity and the impacts of extraterrestrial bodies. Energy stored inside the earth unceasingly flows towards the surface. This concentrated energy is then released over short time periods as volcanoes and earthquakes. Over longer time periods, it has caused formation of continents, oceans and the atmosphere ${ }^{1}$.

Although the earth had its origin about 4.5 billion years ago, these processes are still continuing and natural disasters take place almost all over the world in various forms. By increased utilization of the earth's resources, mankind has begun to significantly influence the global climatic system. The earth's natural green house effect, ozone layer and atmospheric temperature are some of the highly disturbed natural phenomena. These activities lead to more frequent, destructive and dangerous natural disasters causing extensive damage to human lives, human habitats and properties. This paper presents the outcome of a research carried out to study the effects of some selected natural disasters on built environments and methods to improve the disaster resistance. Some simple and cost effective methods are presented as guidelines for enhanced disaster resistance.

\section{Disaster Proneness}

The tectonic location of a country is one of the main governing factors of its vulnerability to natural disasters. Good examples of this are countries like Indonesia and its islands namely, Java, and Sumatra, which are highly prone to frequent earthquakes and volcanic activities throughout the year. The reason for this is that these are located along the Indo-Australian major tectonic plate and Burma micro plate boundaries as shown in Figure 1. These plate margins are represented by the Sunda trench and Sumatra fault line, which are some of the most active 
seismic areas in the world today as shown in Figure 2. When earthquakes of higher magnitudes (generally, the magnitude greater than 6.5 in Richter scale) occur within the ocean, there is a strong possibility for tsunami of some magnitude.

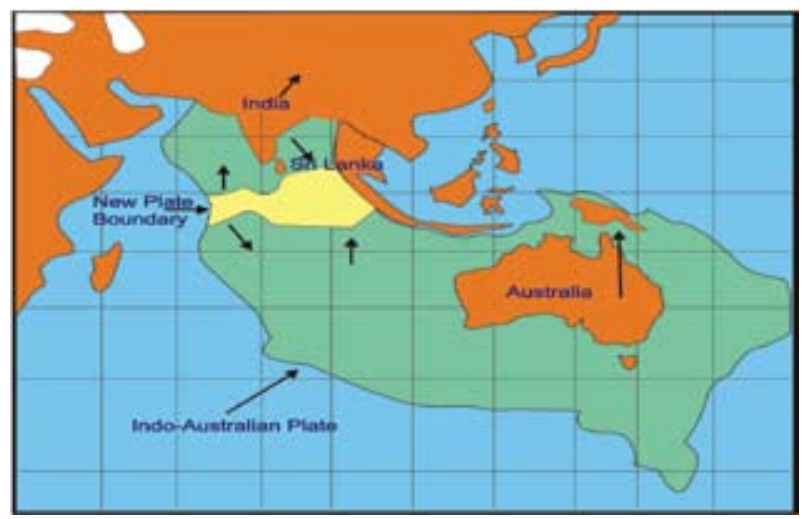

Figure 1: Major tectonic plate settings of the India-Australia region. Recent studies reveal that Indu-Australian plate has separated many millions years ago and now they act as two separate plates. The Australian plate is rotating in the counter clock wise direction by putting stress on the Southern segment of the Indian plate and Western section of Burma micro plate making this triple point tectonic junction a very active seismic area.
Similarly, the regions within the typical cyclone tracks of the world could be subjected to cyclonic effects frequently. Tropical cyclones generally develop between the $10^{\circ}-15^{\circ}$ latitudinal circles. Once generated, the area within the $5^{\circ}-30^{\circ}$ latitudes can be easily affected by these cyclones. The Northern Indian Ocean region (i.e. the Bay of Bengal region where cyclones are generated) is susceptible to these during the months from May to December.

In case of the geometrical location of Sri Lanka, it is on the Indo-Australian major tectonic plate in between $5^{\circ} 55^{\prime}-9^{\circ} 51^{\prime} \mathrm{N}$ latitudes and $79^{\circ} 43^{\prime}-81^{\circ} 53^{\prime} \mathrm{E}$ longitudes, approximately $1600 \mathrm{~km}$ away from the active plate boundary. Therefore, there is little chance for inter-plate type earthquakes to affect Sri Lanka. For example the earthquake close to Indonesia of magnitude 9.3 in Richter scale of $26^{\text {th }}$ December 2004 or 8.2 in Richter scale of $12^{\text {th }}$ September 2007 was not even felt in Sri Lanka except for some minor tremors in few locations. However, the tsunami created by the earthquake of $26^{\text {th }}$ December 2004 devastated the coastal area of Sri Lanka. The earthquake of $12^{\text {th }}$ September 2007 led to the evacuation of many people from the coastal regions. Cyclones could also affect Sri Lanka especially the North and East as shown in the cyclone map of Figure 3. Thus, adopting some disaster resistant measures for built environments against these three types would be appropriate.

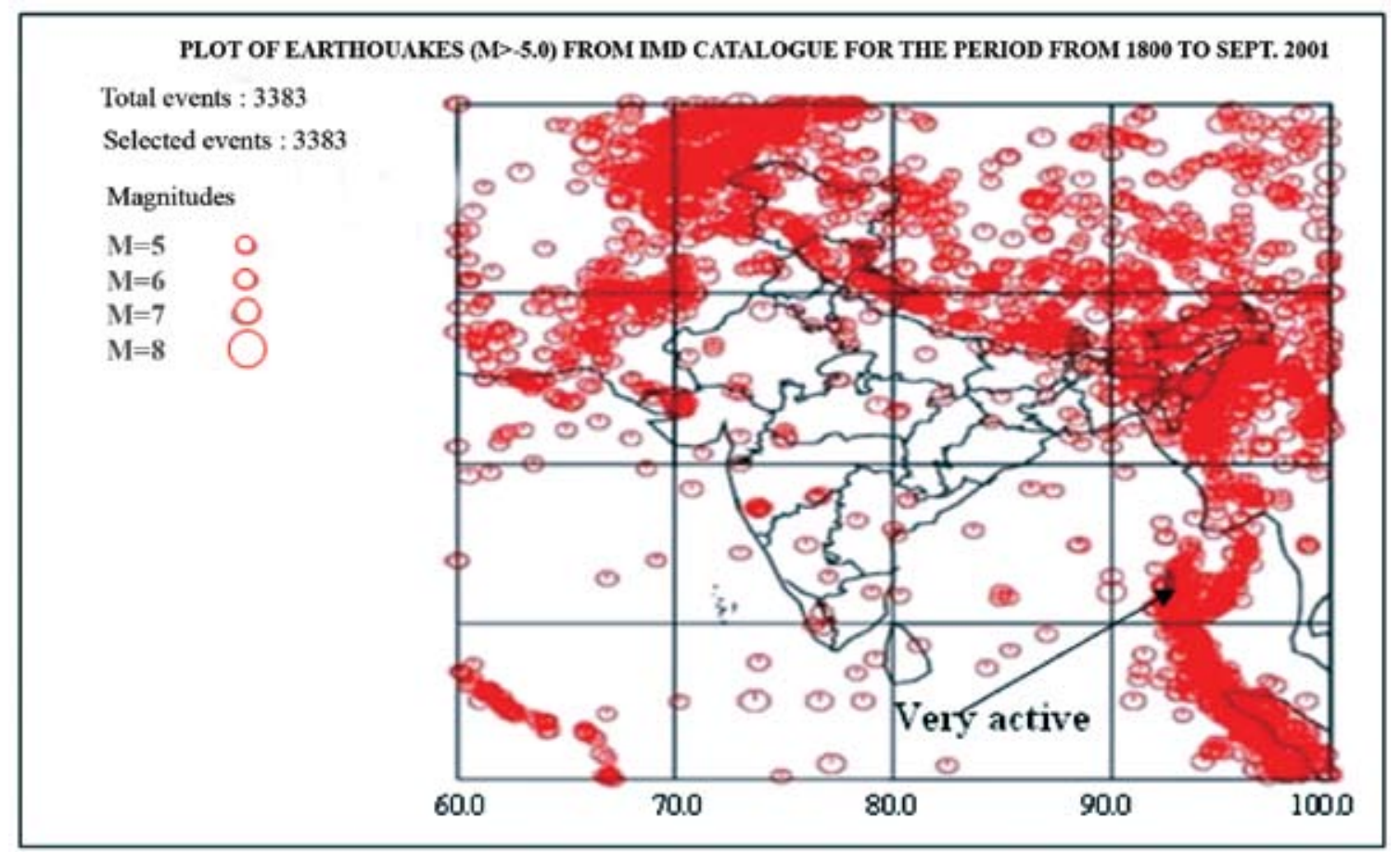

Figure 2: Seismicity in the Northeast Indian Ocean region for the period from 1800 to Sept. 2001. Each dot indicates an earthquake of magnitude greater than 5M in Richter scale Magnitudes are represented by the sizes of the dots. 


\section{Earthquakes}

Earthquakes may be created by volcanic activities, meteorite impacts, undersea landslides, explosions of nuclear bombs, etc. But they usually occur when the rock underneath breaks along a fault line. Fault line is a fracture, a crack in the earth along which the rocks on each of its two sides move against each other. When the stresses built up are large, rocks break and shift along the fault lines. This will generate seismic waves that could cause ground vibrations. This action can be likened to the effect that is visible when a stone is thrown into water, i.e. series of concentric waves that move outwards from the center. Seismic waves too behave like this. This type of movement that leads to build up of energy could create earthquakes well away from known plate boundaries. They are called intra-plate type earthquakes. According to previous studies ${ }^{2}$ a total of 88 such earthquakes have occurred since 1819 to 1988 within an area covered by $2^{\circ}-13^{\circ}$ North latitudes and $76^{\circ}-85^{\circ}$ East longitudes.

When earthquakes occur, they can generate three different types of seismic waves:

1. Primary waves (P-waves)

2. Secondary waves (S-waves)

3. Surface waves (L-waves)
$\mathrm{P}$ waves are responsible for the back and forth movement of the ground and cause relatively low displacements. Further, they are of high frequency, short wave length longitudinal waves which can pass through both liquids and solids. This is the first kind of wave which arrives at any given point after an earthquake. S-waves are responsible for the side ways displacements of walls and fences, giving them $\mathrm{S}$ shaped deformations and displacements on the surface of the earth. These are also of high frequency, short wave length, but are transverse waves. These waves cannot move through liquids and arrive at any given point after the $\mathrm{P}$ waves. $\mathrm{L}$ waves are transverse, of long wavelength with low frequencies. They are generated only within close proximities of the epicenters but are responsible for the majority of damage to the structures due to its wave like rise and fall motion of the ground.

The magnitude of an earthquake is measured on the Richter scale, invented by Charles F. Richter in 1934. The scale is based on the logarithmic scale (base 10), i.e. a magnitude 5 earthquake is 10 times stronger than a magnitude 4 earthquake. The energy released between two adjacent values on Richter scale is proportional to $10^{3 / 2}$ (i.e. $31.6 \sim 32$ ) and generally considered as 32 times.

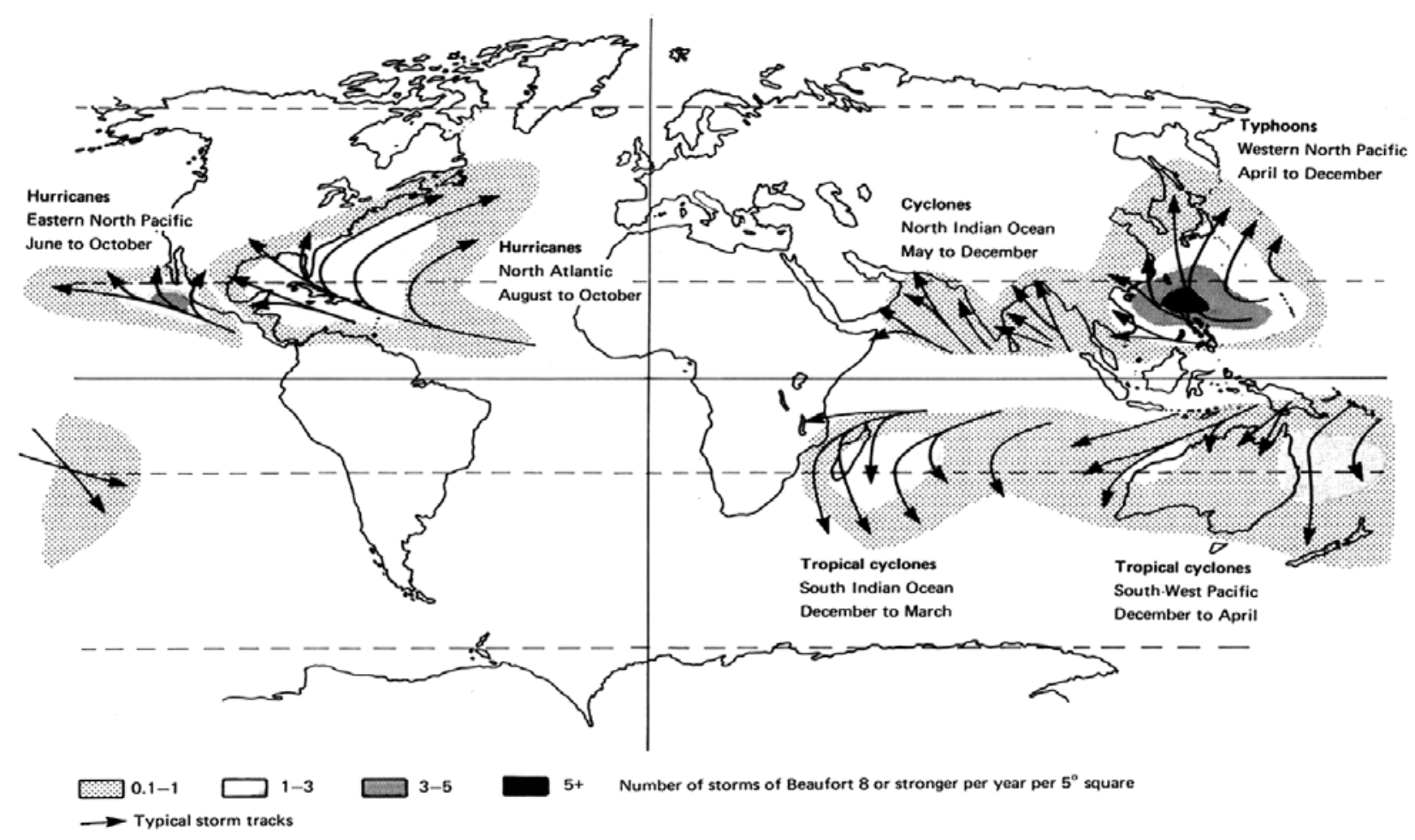

Figure 3: Typical tracks of tropical cyclones in the world. North, North Central and Eastern provinces of Sri Lanka are highly vulnerable for cyclonic effects in the months of May to December 
Sri Lanka is located well away from the major tectonic plate boundaries. Sri Lanka is safe from more frequent and more violent type of earthquakes that are likely to happen along the faults of plate boundaries, i.e. inter-plate type earthquakes. One good example for this is the $26^{\text {th }}$ December 2004 earthquake of $9.3 \mathrm{M}$ in Richter scale, the second largest earthquake ever recorded on seismographs. It was powerful enough to vibrate the whole planet by about half an inch ${ }^{3}$. Even so, Sri Lanka felt minor tremors in few locations only. Past records also indicate that chances of even moderate earthquakes of magnitudes 5.5 M-6.0 M, closer to Sri Lanka, are very remote. However, it is desirable to make structures which could resist some earthquake magnitudes in Sri Lanka since more and more earthquake tremors can be expected due to the increased seismic activities in the region. It is also very difficult to predict the next event and its nature. Nowadays, the earthquake resistant design techniques are being implemented in most of the large building projects and tall structures due to the uncertainty of minor earthquakes affecting Sri Lanka in the near future. The earthquake resistance enhancement techniques that can be adopted for reinforced concrete buildings with respect to structural forms, planning provisions and reinforcement detailing have been presented by in previous studies ${ }^{4}$.

However, the adoption of desirable features in smaller buildings and houses has lagged behind and can be attributed to the fear that earthquake resistance enhancement will have a significant cost implication. A series of measures that could be adopted for masonry construction often used for single and two storey houses has already been presented ${ }^{5}$.

\section{Cyclones}

Changes in global climatic patterns resulted in more frequent cyclone warnings over the past few years. On $24^{\text {th }}$ of November 1978 and $26^{\text {th }}$ of December 2000, there were two severe tropical cyclones that swept in from the Bay of Bengal across the Northern, North Central and Eastern provinces of Sri Lanka with resulting wind speed reaching up to $150 \mathrm{kmph}$. Many people were reported

Table 1: Normal and post disaster wind speeds for 3 different wind zones in Sri Lanka

\begin{tabular}{ccc}
\hline \multirow{2}{*}{ Zone } & \multicolumn{2}{c}{${ }^{2}\left(m s^{-1}\right)$} \\
\cline { 2 - 3 } & Normal speed & Post disaster \\
\hline Zone 1 & 49 & 54 \\
Zone 2 & 42 & 47 \\
Zone 3 & 33 & 38
\end{tabular}

dead and more than half a million people were forced to flee their homes due to the $24^{\text {th }}$ of November 1978 cyclone. Approximately 83,000 houses have been either damaged or destroyed from this catastrophe within a $150 \mathrm{~km}$ long belt from Tirukkovil to Trincomalee. Severe damages were also caused to the infrastructure facilities such as, power supply, transportation and communication. Since a disaster of this nature had never been known prior to this time, the damage to both human lives and property were enormous. Figure 3, which indicates the typical cyclone tracks in the world, can be used to explain the higher vulnerability of northern and eastern provinces for cyclones.

Cyclonic storms occur when the sea surface temperature exceeds $27^{\circ} \mathrm{C}$ for extended periods which can be attributed to many cyclones originating in the Bay of Bengal. This is similar to the tropical Atlantic hurricanes. The rise in temperature sets up wind systems which generate enormous amounts of energy.

After the November $24^{\text {th }} 1978$ cyclone, three basic wind speed values were established by dividing Sri Lanka into three different wind zones as indicated in Table 1. The post disaster wind speeds are for the design of important structures such as hospitals, fire brigade, etc. where post disaster recovery actions need to take place. Generally, two wind speeds are not necessary since the normal wind speed can be multiplied by 1.1 for post disaster structures according to the AS 1170: Part 2: $1989^{6}$.

Zone 1 can be identified as the area where major towns like Jaffna, Trincomalee, Batticaloa, Kalmunei, Amparai are located and the area within a $50 \mathrm{~km}$ band from the eastern coastal line. Zone 3 consists of all towns west of Puttlam, Anuradhapura, Dambulla, Matale, and Kataragama. The major towns like Colombo, Kandy, Kurunegala, Galle, Matara, Nuwara-eliya and Bandarawela also fall within Zone 3. Zone 2 includes

Table 2: Tsunami classification [12]

\begin{tabular}{ccl}
$\begin{array}{c}\text { Tsunami } \\
\text { magnitude } \\
\mathrm{m}\end{array}$ & $\begin{array}{c}\text { Tsunami height } \\
\mathrm{H}\end{array}$ & Damage \\
-1 & $50 \mathrm{~cm}$ & $\begin{array}{l}\text { None } \\
\text { Very little damage } \\
0\end{array}$ \\
1 & $1 \mathrm{~m}$ & $\begin{array}{l}\text { Coastal and shipping damage } \\
\text { Damage and lives lost in cer } \\
2\end{array}$ \\
$4 \mathrm{~m} \sim 6 \mathrm{~m}$ & $\begin{array}{l}\text { tain land areas } \\
\text { Considerable damage to the } \\
\text { coastal areas } \\
\text { Massive damage to the coastal } \\
\text { areas }\end{array}$ \\
\hline
\end{tabular}


the rest of the areas between Zones 1 and $3^{7}$. Figure 4 indicates the three different wind zones in Sri Lanka ${ }^{8}$.

\section{Tsunami}

The word tsunami has originated from the Japanese language, meaning "Large harbour waves". This is the biggest and more feared kind of waves. It cannot be noticed in the open sea, but suddenly rise up in shallow water closer to the shoreline and strike large costal areas. Tsunami waves are generated mainly due to sudden displacements of the sea bottom which in turn makes a vertical disruption of a large water column. This is mainly due to under sea earthquakes. But volcanic eruptions, displacements of marine sediments, landslides near the coast and meteorite impacts are also responsible for these waves ${ }^{9}$. Globally, the highest concentration of tsunami occurs around the rim of the Pacific Ocean in the Australia-Asia region ${ }^{10}$. Japan is subjected to severe earthquakes each year as it strides three tectonic plates, which subduct into the mantle. But only some are tsunamigenic and most tsunami are localized.

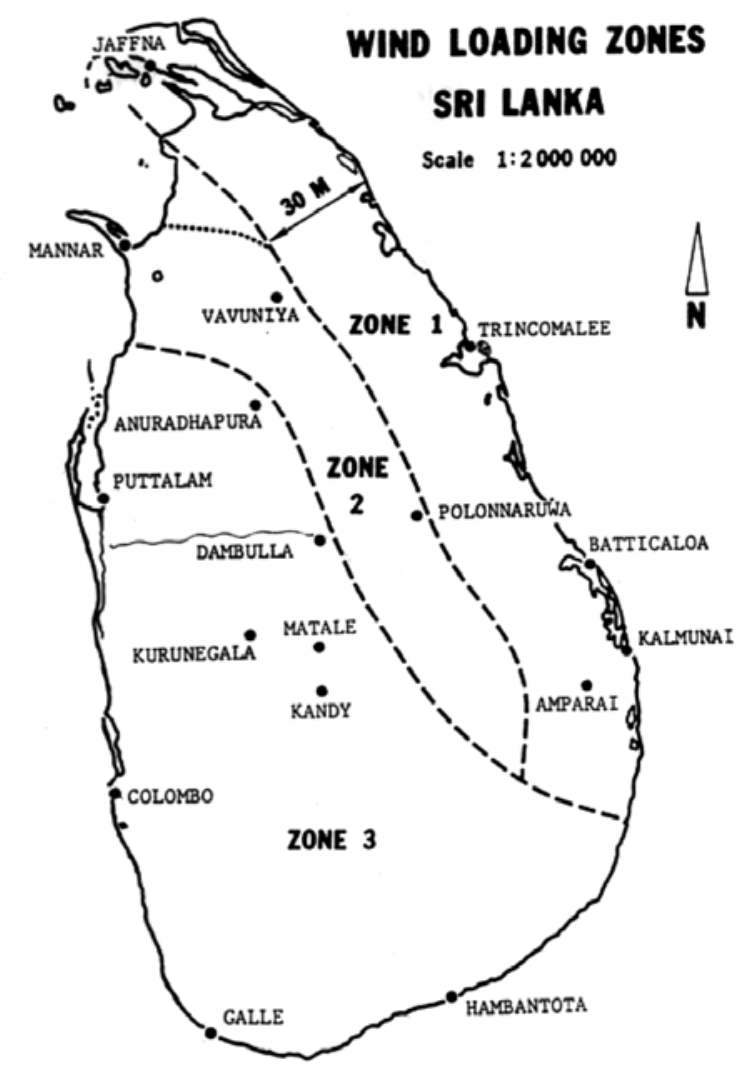

Boundaries As Proposed By Sri Lanka Cyclone Regularions Compit

Possible Modifications to Above Boundaries

Figure 4: Wind loading zones in Sri Lanka ${ }^{8}$, Scale 1:2 000000
Several relationships exist between the magnitude of an earthquake and the magnitudes of tsunami waves it can generate. If the magnitude of a Tsunami is expressed as "m", one such relationship is,

$$
\mathrm{m}=2.61 \times \mathrm{M}-18.44
$$

Where, "M" is the magnitude of an earthquake defined by the Richter scale.

A previous study ${ }^{11}$ has illustrated one classification system of the strength of the tsunami expressed as a magnitude " $\mathrm{m}$ " and it is shown in Table 2 . When Tsunami waves reach shallow waters, the wave speeds will be reduced but the heights can increase rapidly due to minimum amount of energy loss. Sri Lanka having a very narrow continental shelf, had not reflected a significant amount of wave energy during the last Tsunami on the $26^{\text {th }}$ of December $2004^{11}$. The wave energy that transmitted over the continental shelf had moved towards the land with devastating power and destruction. Therefore, it is essential to have natural energy dissipaters like coral reefs, mangroves grown on the shore line, sand dunes, etc. When coral reefs are present, they will act as a natural submerged breakwater and dissipate the wave energy $^{12}$. The waves have gone up to $15 \mathrm{~m}$ from the mean sea level in some parts of the Eastern coast. But most of

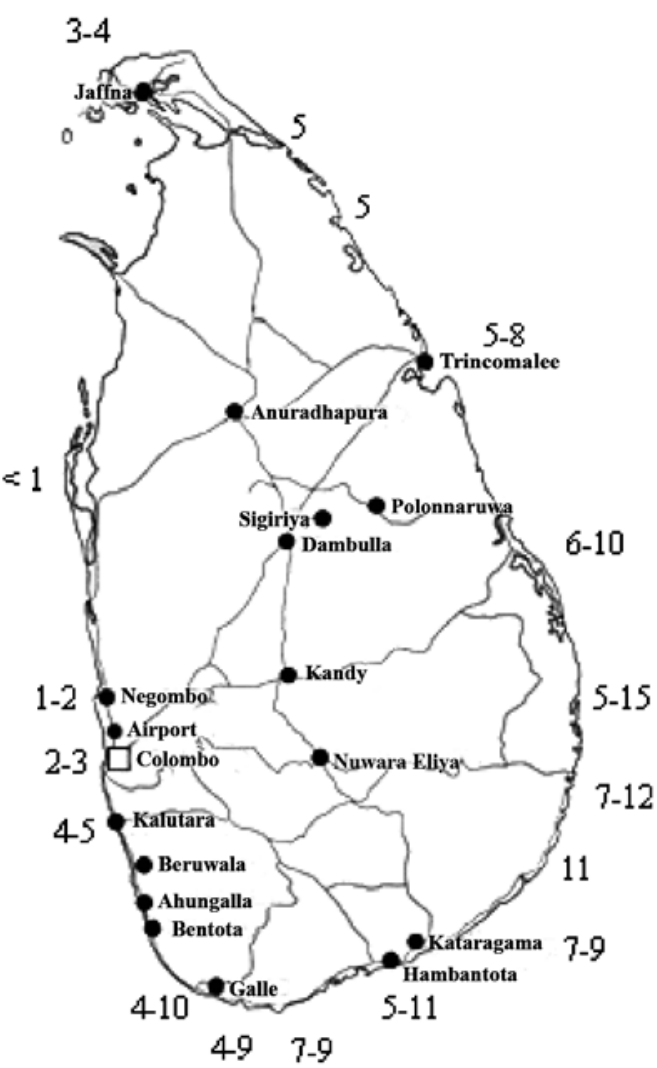

Figure 5: Recorded tsunami wave heights in meters [12] 
the typical structural damages were due to wave heights of less than $15 \mathrm{~m}$. In many places the wave heights were within the range of 2-5 $\mathrm{m}$ from the structural foundation levels ${ }^{13}$. Figure 5 shows the estimated wave heights from the mean sea level in the tsunami affected coastal areas in Sri Lanka.

The danger from future tsunami and earthquake tremors in Sri Lanka is also mainly due to the high seismicity in highly active Sunda trench and Sumatra fault. The major reason for high seismicity is the location on or closer to the triple junction among the tectonic plates. On December $26^{\text {th }}$ of 2004 , one such massive tsunami struck a $1126 \mathrm{~km}$ area of the costal belt of Sri Lanka, causing a catastrophic level of destruction in 13 of the 25 districts. According to the records published in 2005 by the Department of Census and Statistics of Sri Lanka, this tsunami disaster had caused a death toll of over 36,000 and out of this 30,957 people were listed as dead and 5644 were listed as missing. An estimated total of 800,000 people were displaced ${ }^{14}$.

\section{Damage level}

The built environments under these three adverse forces of nature have shown either minor structural damages or partial collapses or complete failures, depending on the magnitude of the forces. Therefore, the issues that have been commonly addressed and the reasons discussed for them in this paper will be common to most cases. Lack of awareness of the general public on the effects from various loading conditions that act on structures due to natural disasters and their responses under these kinds of disastrous situations are two of the main reasons for the loss of life and property damage.

In this paper some commonly identified structural damages are discussed with photographs. These structural damages were identified from several field studies carried out after the natural disasters. Most of the photographs were taken after the $26^{\text {th }}$ of December 2004 tsunami in coastal areas such as Amabalangoda, Hikkaduwa, Galle, Matara, Tangalle, Yala, Ampara, Kalmunei and Batticaloa. Various types of structural damages that occurred due to natural disasters are given in the following sections.

\section{Non engineered masonry brickwork structures}

Burnt clay bricks are the most widely used material in house construction in many parts of Sri Lanka. Due to wider availability, ease of use and rapid construction, they have gained popularity among many builders. The single story and two storey houses and other structures made out of this are "non-engineered" in many cases.
A range of damages possible are from small structural damages to the complete collapses.

Figures, 6, 7, and 8 show some of the common structural damages that occurred after the tsunami waves. According to previous studies ${ }^{15}$, the types of failures in these kinds of non-engineered structures are mainly due to the lateral pressure exerted on walls from filled up water, uplift caused by filled up water, floor slab failures due to erosion of foundations and also due to liquefaction of sandy soils under the foundations.

\section{Typical foundations of single storey houses}

In coastal areas, sandy soil conditions are common. Sandy soil is considered as an ideal material for locating foundations of single storey houses due to its reasonably high bearing capacity even when the water table is high. However, the situation created by tsunami waves showed special characteristics such as rapid build up of pore pressures and scouring action. Where shallow foundations were located on sandy soils, they were affected to a significant level that led to the collapse of many houses.

Since it is not practically possible to change the main soil type, the foundations of houses built on sandy soil will need certain precautions that will minimize the chances for liquefaction or scouring. These are presented under the guidelines indicated in this paper.

In some cases where the foundations were rigid enough, the wall panels have completely washed away due to inadequate bond between walls and the plinth beam when subjected to excessive lateral loads. Figure 9 shows a picture of a damaged single storey masonry building in which all the walls have washed away from tsunami tidal waves.

\section{Foundations of reinforced concrete structures}

Sandy soil conditions are generally considered as reasonably acceptable soil even for the foundations of low rise reinforced concrete framed buildings of 3-4 stories. Owing to good bearing capacity, isolated pad footings are often used at shallow depths. There is a strong tendency to have a plinth beam at ground floor level to tie all the isolated pad footings. Such foundations have also suffered severe damage primarily due to liquefaction and scouring caused by rapidly moving waves. Thus, even the reinforced concrete structures would need some precautions to prevent such damage when located in areas with sandy soil. One of the main observations was that the scouring damage was generally limited to about $1.0 \mathrm{~m}$ below the existing foundation 


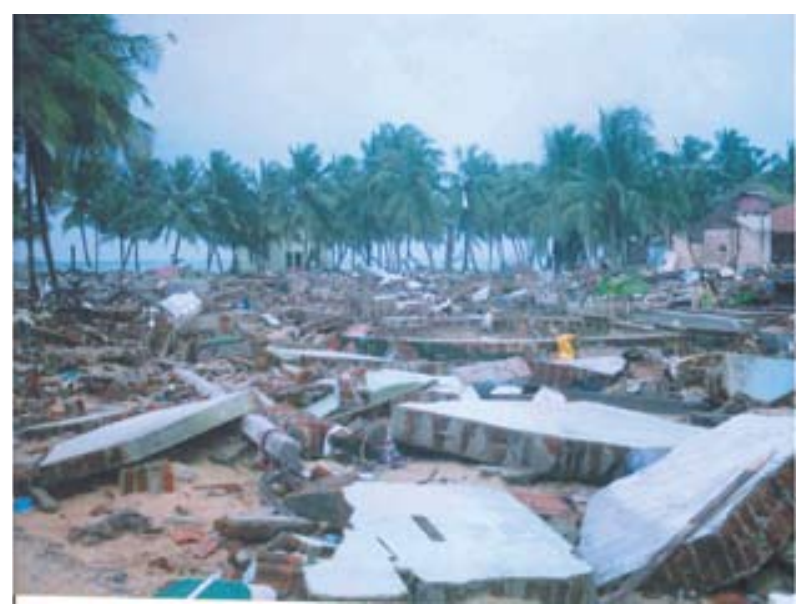

Figure 6: Completely collapsed brickwork structures due to tsunami tidal waves in Kalmunei

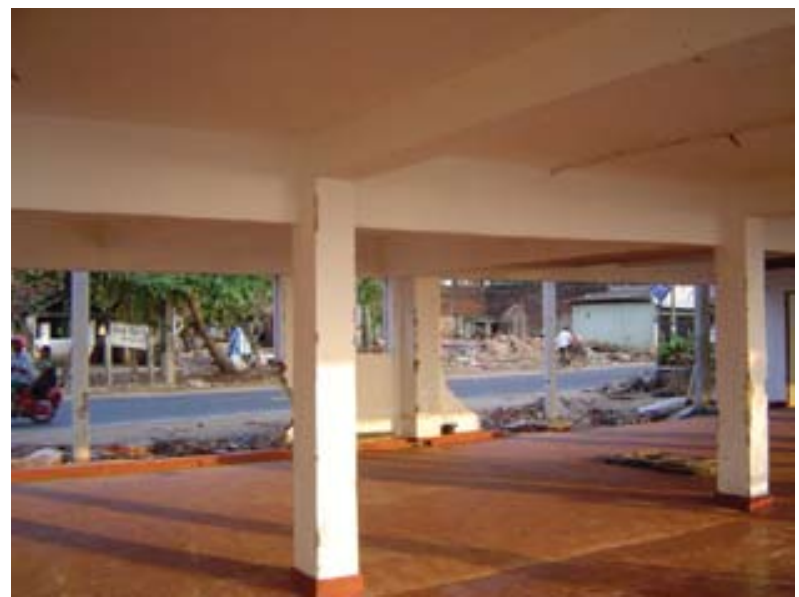

Figure 8: A structure of a building survived with minimum damage. Only the infill masonry panels have collapsed from tsunami waves

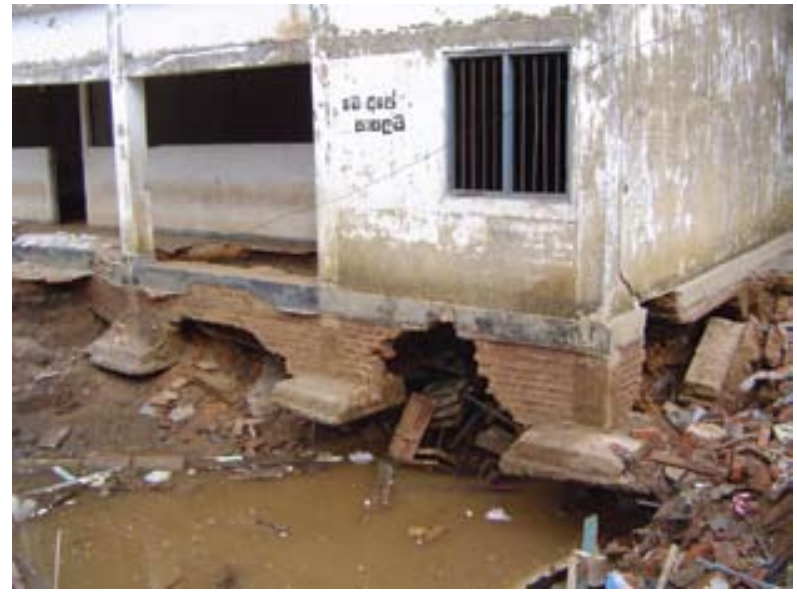

Figure 10: Under-scouring of foundation at a corner of a school building from tsunami waves

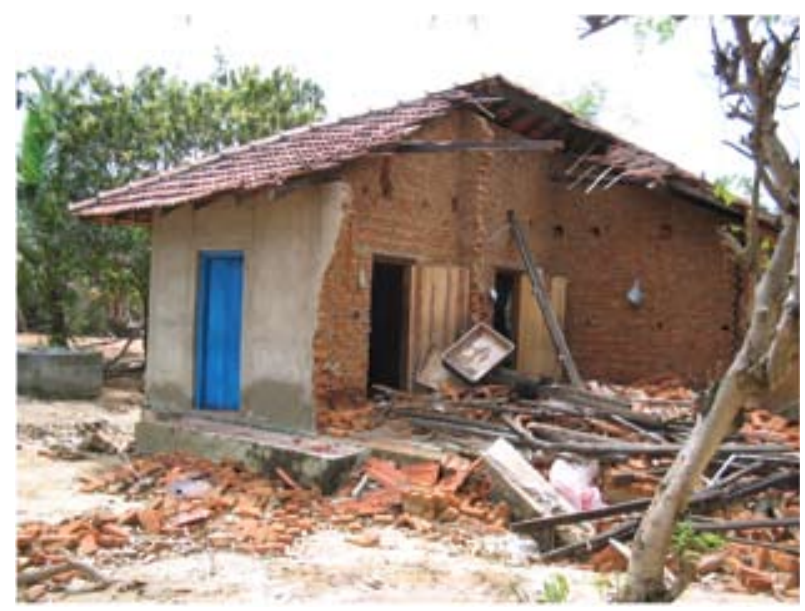

Figure 7: Partially collapsed brickwork structures due to tsunami tidal waves in Sri Lanka

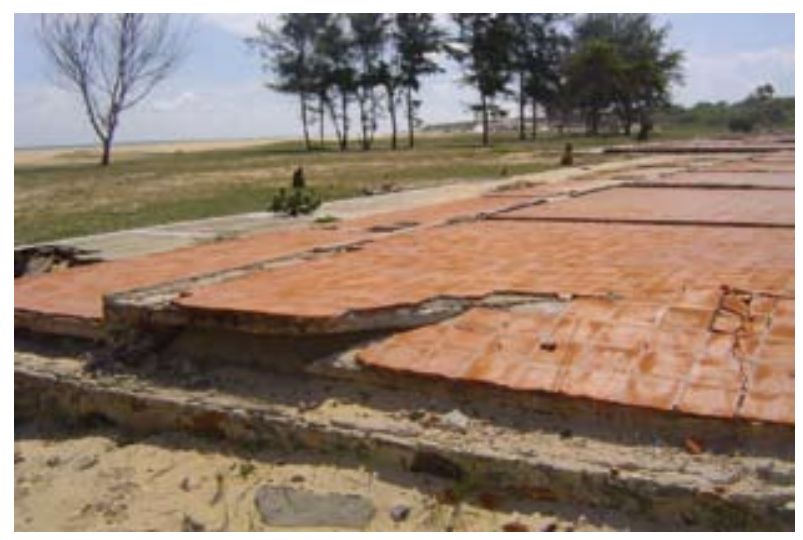

Figure 9: Failure of a masonry low rise building in Yala-Safari Beach Hotel, Yala, due to tsunami waves

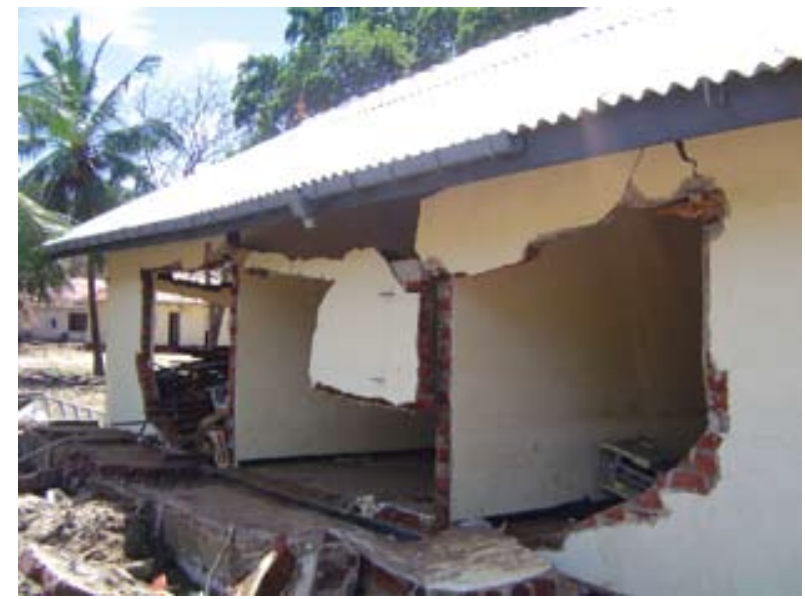

Figure 11: A house close to the shoreline, its long weaker side facing the sea coast 
level. Figure 10 shows a picture of a school building with isolated pad footings. It shows how severe the scouring action can be at a corner of a building like this due to the formation of eddies in waves.

\section{Window and door openings in wall panels}

The window and door opening locations are generally selected giving priority to satisfy the minimum requirements of building regulations, aesthetics and functionality. Very little attention is usually given to the structural aspects. However, provision of openings could give rise to higher stresses closer to the openings. If careful attention is not paid on the size and spacing of openings, it can lead to serious structural damage in case of both in plane and out of plane stresses caused by lateral loads. In order to reduce such adverse stresses, various guidelines can be used.

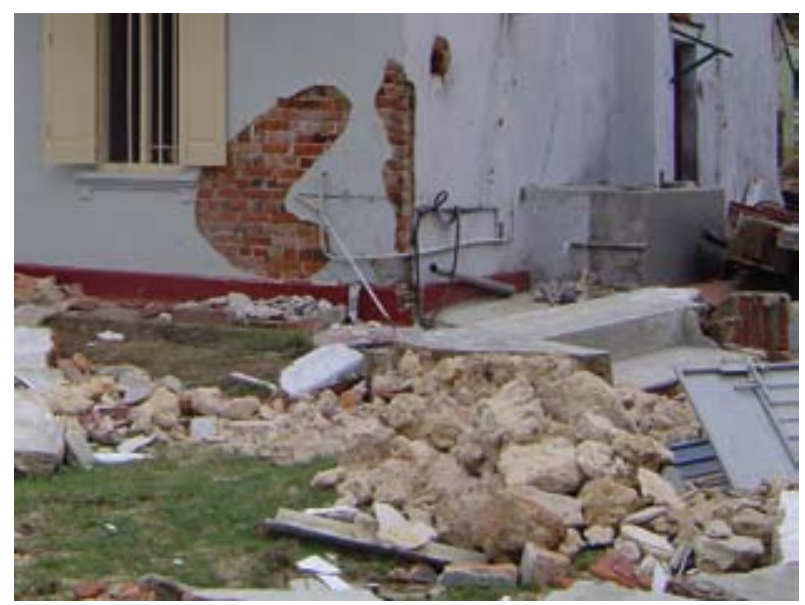

Figure 12: A house close to the shoreline, its short and stiffer edge facing towards the sea

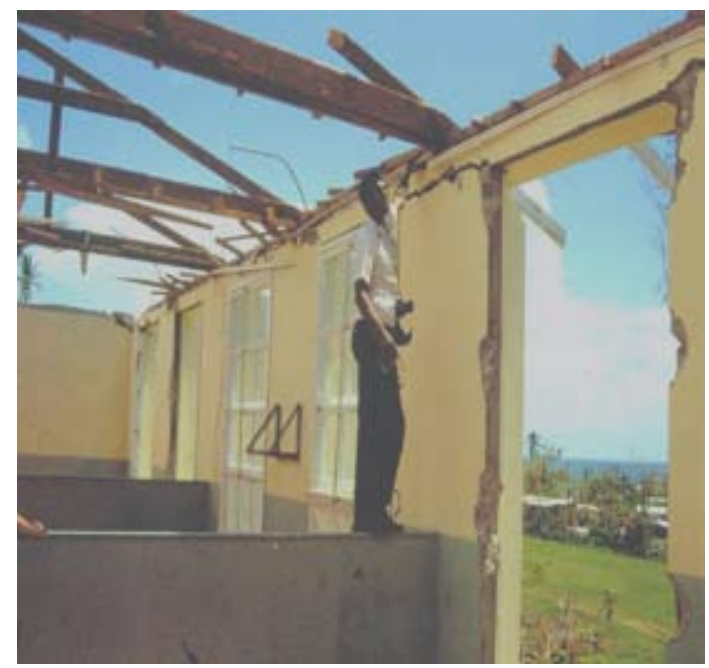

Figure 13: Single storey building; asbestos roof has blown away due to a cyclone
According to the guidelines published by the National Housing Development Authority, the total length of openings should not exceed $50 \%$ of the length of wall sections span between two consecutive cross walls for single storey, $42 \%$ for two storey and $33 \%$ for three storey houses ${ }^{16}$. Further to that, similar values have been given as guidelines in Great publications ${ }^{17}$, and in the guidelines published by the Government of Tamil Nadu ${ }^{18}$. One common bad construction practice that could be observed in most of the damaged structures due to tsunami tidal waves was the discontinuity of the lintels above the openings. Instead of a continuous lintel beam, segments were used above door and window openings. It is desirable to have all the top levels of these openings at a single elevation enabling a continuous concrete lintel band to be easily placed. This will give higher rigidity to the entire structure.

The orientation of the building also plays a major role with respect to the structural performance. In case of heavy and gusty winds, frequent floods, and tsunami waves, it is more desirable to have the shorter or the stiffer edge facing them. Figures 11 and 12 provide some evidences on the effect of orientation of a building against its structural performance under excessive loading conditions. Both these houses were close to the shore line. The house where the front wall with many openings facing the sea, (shown in Figure 11) suffered severe damage. In the house shown in Figure 12, the short and stiffer walls well supported by walls located perpendicular to it, suffered much less damage. This indicates that the enhanced lateral load resistance is highly beneficial in resisting lateral loads that occur in extreme events of nature.

\section{Failures of roof structures}

Failure of roof structures is generally associated with cyclones. However, the tidal waves caused by tsunami of

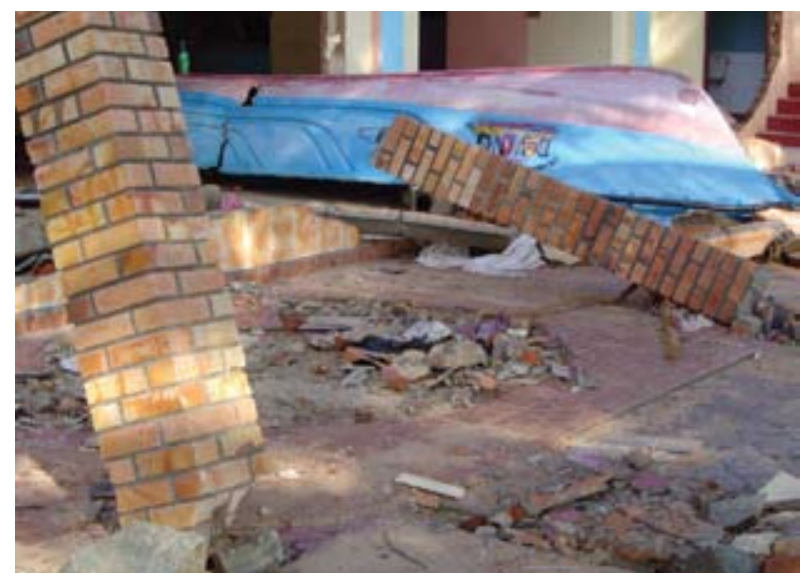

Figure 14: Damage due to a boat taken from tsunami waves 
significant height could also affect the roofs. According to the survey data of Department of Census and Statistics of Sri Lanka, most widely used roof covering material in Sri Lanka is burnt clay tiles (57\%). Cement fiber sheets are the second most popular roof covering material $(15 \%)^{19}$. In the event of severe winds, these roofs can be subjected to uplifting forces. Figure 13 shows a picture of a single storey house in which the cement fiber sheet roof has blown away from heavy winds. This type of roof failures could be observed at least in 2,3 places every year due to high wind conditions. Some recent events were in November and December 2007.

For roof covering materials and structure, a suitable anchoring mechanism is an effective way of resisting the uplifting forces. The proper guidelines have been developed after the 1978 cyclone. However, they have not been adopted for majority of the houses due to various reasons such as lack of awareness and sometimes ignorance.

\section{Damage due to floating debris}

Floating debris can cause severe damage during flooding, cyclonic and tsunami situations. Part of the debris is due to damaged buildings and hence ability to minimize damage could assist in reducing such damage. However, there can be other objects which can come and hit along with water or wind such as the boat shown in Figure 14. These things can cause serious structural damage due to impact loading.

\section{Guidelines to enhance disaster resistance}

It is useful to undertake field surveys after a natural disaster to assess the damage to the built environments and also to determine the causes for such damages. Such studies can then be extended to develop strategies for enhanced disaster resistance. This section of the paper describes the enhancement of disaster resistance to minimize such structural damages. The proposed measures are presented as guidelines under each type of disaster, which can affect built environments.

\section{Guidelines for earthquakes}

Minor earthquake tremors primarily due to intra-plate type could be expected in Sri Lanka. Such earthquakes could apply significant dynamic forces over small durations of about 20-30 seconds. These forces could disintegrate foundations unless sufficient tensile force carrying capacity is available. It is also possible to separate the walls of super structures so that the walls will behave as independent members. This may cause some walls to behave with relatively weaker modes such as out of plane. If the walls act together, such out of plane loads can be transferred as in plane loads to the return walls located at right angles. Any type of masonry commonly used in Sri Lanka such as burnt clay bricks, cement sand, compressed stabilized earth, bricks and blocks, etc. are capable of resisting significantly high in plane loads, but relatively weak in resisting out of plane lateral loads.

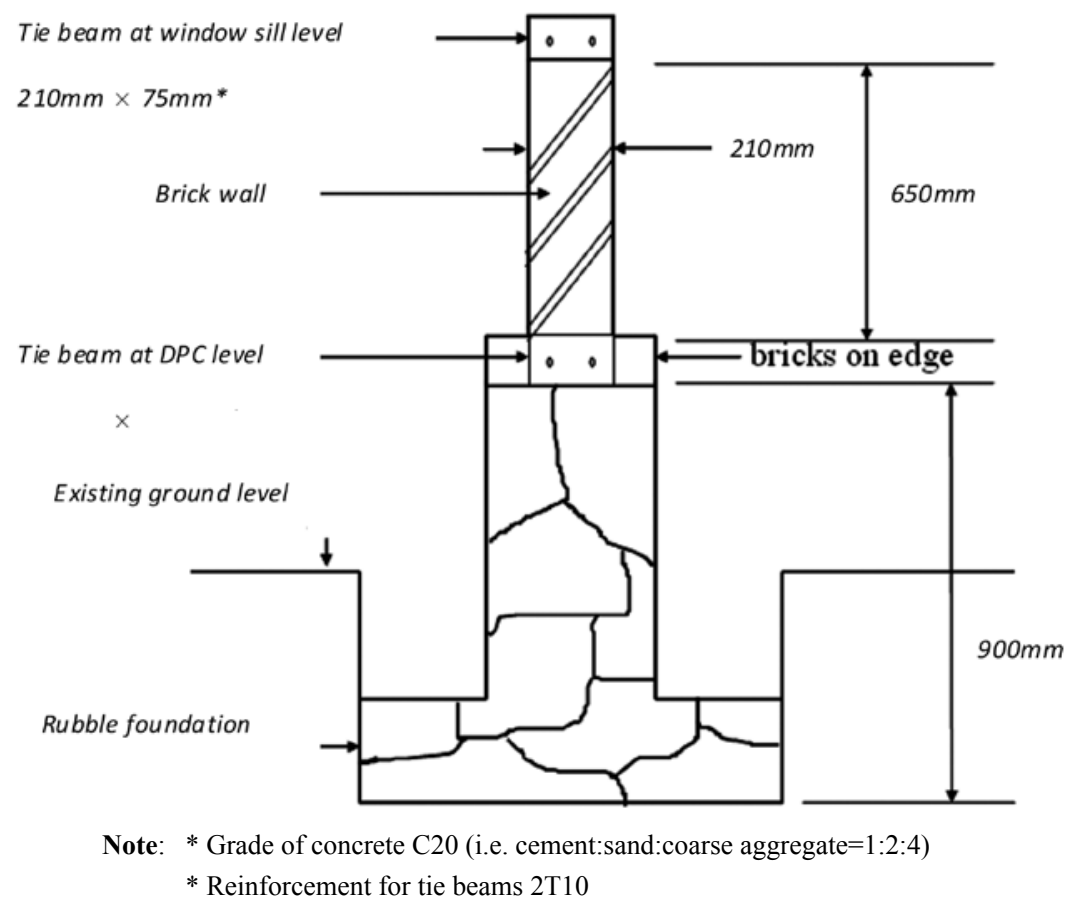

Figure 15: Rubble foundation with tie beams at DPC (Damp proof course) and window sill levels 
This means that the remedial action must prevent the disintegration of walls and the foundation. This will need continuous tie beams which can tie the external and internal return walls together.

The preferred locations for such tie beams are the following:

1. Plinth level above the foundations

2. Lintel level as a continuous beam above the openings, connecting all internal and external walls

3. Window sill level

Another type of damage which is possible from earthquakes is the liquefaction of sandy soil. When earthquakes occur with their epicenters within or very close to the land and when the ground water table is also high, the liquefaction effects can be multiplied. This can reduce the bearing capacity of the soil to very low levels, momentarily. This can be easily prevented when the sand with coarse particles is mixed with low contents of laterite or any other granular soil so that the presence of clay particles within a dense skeleton of sandy particles will prevent the rapid development of pore pressures. However, fortunately the chances of this kind of an earthquakes happening with its epicenter located inland is very remote in Sri Lanka, as mentioned earlier in this paper.

When reduction in foundation bearing capacities are anticipated, it is important to ensure that the foundation will be strong enough to transfer loads from weaker regions to stronger regions until the soil regains the strength. This could be achieved by providing a continuous tie beam at the window sill level which acts in conjunction with the tie beam at plinth level and the foundation rubble work, to minimize the local deformations and hence cracking of walls. An arrangement of the proposed foundation system is shown in Figure 15.

\section{Guidelines for cyclones}

Cyclones could uplift light weight roofs. This was evident from the damages caused in the 1978 cyclone with greater damage to the cement fibre sheet and galvanized iron roofs. The solution to this is anchoring of the roof supporting structure and the roof covering materials to the walls and finally to the foundations. This is the solution recommended especially for houses located in Northern and Eastern parts of Sri Lanka.

An alternative to the above is, the use of stub columns with at least 1 number of T10 bars that could be used for anchoring of the roof structure. In order to prevent uplifting, it is essential to ensure that sufficient weight is available as the self weight of the walls above the continuous lintel. This could be achieved economically by raising the internal partition walls and the external walls sufficiently.

Preliminary studies indicate that a wall height of 600 $\mathrm{mm}$ to $1000 \mathrm{~mm}$ would be needed above the lintel level depending on the type and width of building materials (brick work, hollow block work or solid block work) ${ }^{20}$. This may change the manner in which future houses are designed since the present practice is to have only about $300 \mathrm{~mm}$ of wall height above the lintels and also to stop the internal partition walls at ceiling level. Such practices will not provide adequate support to the gable walls as well. Thus, these weaknesses should be minimized with increasing heights of internal and external walls above the continuous lintel levels which could ensure adequate weight that would resist cyclone induced uplifting forces.

\section{Guidelines for tsunami}

Tsunami generated tidal waves could have heights of up to $15 \mathrm{~m}$. It is not practical to resist wave heights of over $3 \mathrm{~m}$ with single or two storey buildings. Waves up to $3 \mathrm{~m}$ could cause partial or complete submergence for a short duration and if such forces could be resisted for a sufficiently long duration, the structure stands a chance of surviving a tsunami. This will need a sufficient lateral load carrying capacity for the walls. It could be provided by the tie beams at various locations provided for enhanced earthquake resistance.

Another option available is the construction of elevated houses using a suitable arrangement of reinforced concrete columns as shown in Figure 16. However, this will have a significant increase in cost for a single storey house. This house will need sufficient number of brick walls to provide lateral stability needed against lateral loads induced by earthquakes. As shown in Figure 17, this type of localized effect can be expected from earthquake induced base shear forces. This picture was taken at Beralihela, Tissamaharamaya after few earthquake tremors on $9^{\text {th }}, 20^{\text {th }}$ and $21^{\text {st }}$ July 2007.

Both options mentioned above have the risk of being affected by foundation failures that arise due to serious scouring or liquefaction on sandy soil conditions. The foundation failure occurs due to the rapid development of pore pressure beneath it, especially in sandy soils. Clayey soils will be affected to a much less extent since the impervious soil will not allow rapid changes in pore pressure levels. Thus, a possible solution would be to use a layer of clayey soil immediately below the foundation. However, this is not desirable since clayey soils could give rise to settlements. Thus, a compromising solution is to 
mix sandy soil with laterite soil and to re-compact within the foundation. This will allow the house to have a foundation that is sufficiently deep, but resting on soils less susceptible for liquefaction. This can be considered as a cost effective solution since extra expenditure is needed only for soils to create a stable foundation for normal loads and wave generated conditions. Another serious effect on foundations is the scouring of sandy soil around the house. This also could have the same solution where sandy soils mixed with laterite soil could be used to create a relatively thick bed of top soil around the house. This is an economical solution that can be easily adopted with prevailing construction practices.

\section{An integrated approach}

The effects of tsunami generated waves, cyclones and earthquakes on a house vary to a certain extent. Thus, it would be advisable to have an integrated approach which will be able to deal with different types of natural disasters with minimum cost increases. The solution presented for foundations would be ideal for enhanced resistance against tsunamis and earthquakes. The provision of tie beams and continuous lintel will prevent disintegration of walls during earthquakes while providing enhanced lateral resistance against cyclones. The use of stub columns to prevent uplifting can assist with enhanced stability to gable walls. All these discussions indicate that enhanced disaster resistance measures should not be adopted to respond to a particular disaster, but ideally an integrated approach should be adopted where the house will be able to resist all types of forces due to the most probable disasters. In this paper, an approach is presented for three common types of disasters that are likely to affect single storey and two storey houses in low altitudes and especially close to the coastal areas with sandy soils.

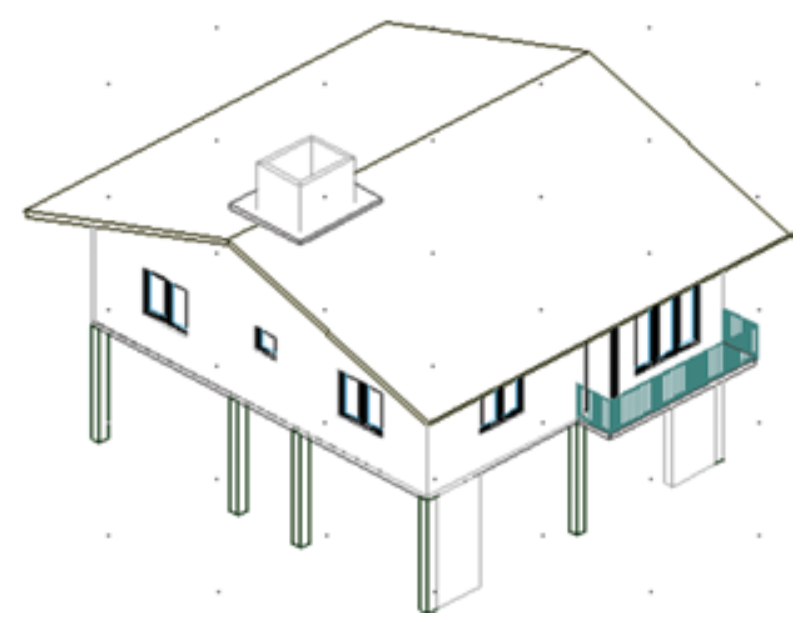

Figure 16: An elevated house which is suitable for low lying flood prone areas and coastal areas.

\section{Cost increases of adopting disaster resistance guidelines}

For single storey houses, cost is a major fact that influences the decisions made during construction. The guidelines presented for foundation improvement with laterite soils will need extra labour and soil. The tie beams at foundation, window sill level and continuous lintels above openings will incur an extra cost. The use of stub columns for anchoring the roof will also lead to some extra cost. All these indicate additional costs which can be expressed as a function of total structural cost. It will be able to indicate the cost penalty needed with capital cost for a house with acceptable level of disaster resistance. The detailed cost studies carried out for a number of single storey houses with the integrated approach indicate extra costs in the range of $4-5 \%$ of the initial capital cost for structure. Since the structural cost is about $40-50 \%$ of the overall cost, the cost increase with respect to overall cost may be less than $2-3 \%$.

\section{CONCLUSION}

The major types of disasters mentioned above which could affect Sri Lanka indicate the need in sufficient disaster resistance in houses to protect both lives and property when these extreme events of nature occur. Various solutions are available for different types of disasters. However, it is difficult to predict which disaster will occur when. Therefore, all the different solutions must be integrated and presented as a common solution.

The following broad guidelines should be followed in house construction:

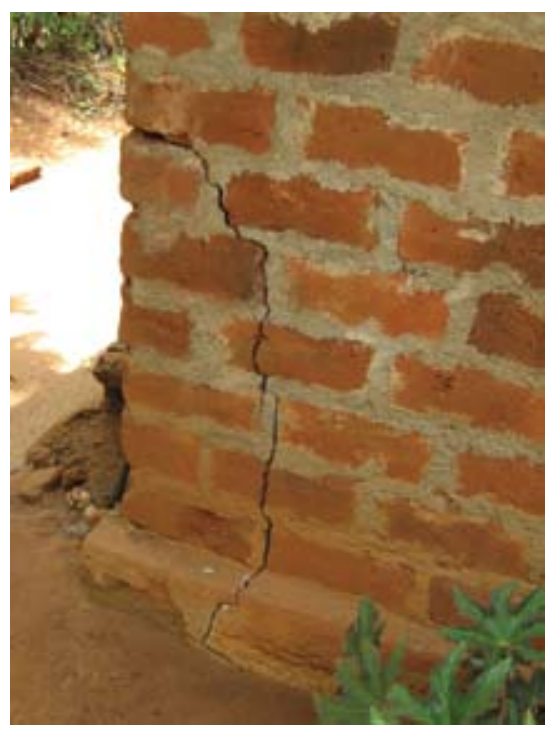

Figure 17: A masonry house subjected to earthquake induced ground motion- Beralihela, Tissamaharama 
1. Ensure that foundations are strong and capable of keeping the structure intact even if temporary reduction in soil bearing capacities occur. For this a typical foundation (shown in Figure 15) can be used with modification to the dimensions depending on the soil conditions. It it is always good to have the foundation widths at least twice the width of the wall section.

2. The walls must be tied together so that the extreme forces are resisted utilizing the desirable strength properties such as in plane flexural or compressive stresses, but not out of plane behaviours.

3. Ensure that the roof structure and roof covering materials are properly anchored to the walls so that chances of uplifting during cyclones will be minimum. For this, sufficient wall heights must be provided over continuous lintels for which the stub columns are needed for anchoring. These must be considered as an integrated approach for enhanced disaster resistance of future houses.

\section{Acknowledgement}

Authors thank the National Science Foundation (NSF) of Sri Lanka for providing funds for this survey. The technical assistance of Messrs S.P. Madanayake, S.L. Kapuruge, and G.T.V. Somarathne of the University of Moratuwa is very much appreciated. The GS of Beralihela area, Mr. Senarath and all the other persons who helped us in many ways are appreciated for their help to make a success of this research.

\section{References}

1. Abbott P.L. (1996). Natural Disasters, San Diego State University Wm. C. Brown Publications, USA.

2. Abayakoon S.B.S. (1998). Seismic response of low lying areas in Colombo, Sri Lanka, Journal of the Institution of Engineers, Sri Lanka 28(2): 29-36.

3. http://en.wikipedia.org/wiki/2004_Indian_Ocean_earthquake, Accessed on 01.08.2007.

4. Perera D.F.U. \& Jayasinghe M.T.R. (1999). Earthquake resistant detailing for reinforced concrete buildings constructed in Sri Lanka, IESL Transactions - Part 2 Institution of Engineers of Sri Lanka, October 1999.

5. Wijeratne M.D. \& Jayasinghe M.T.R. (1999). Earthquake resistance of load bearing brickwork structures, Proceedings of symposium on Research for Industry, University of Moratuwa, Katubedda. December 1999.

6. A.S.1170 (1989). Minimum design loads on structures; Part 2: Wind Loads, Standards Australia, New South Wales, Australia.

7. Jayasinghe M.T.R. (1997). Load bearing brick work construction for Sri Lanka. pp.73, STRAD Consultants (Pvt) Ltd, Colombo.
8. Macks K.J., Murray F.J. \& Wittenoom R.A. (1979). Technical Assistance to Sri Lanka on Cyclone Resistant Construction, Vol. 3, part 6, Australian Development Assistance Bureau, Department of Housing and Construction.

9. Harinarayana T. \& Naoshi Hirata (2005). Destructive Earthquake and Tsunami in the Indian Ocean, What Next? Gondwana Research (Gondwana Newsletter Section), International Association for Gondwana Research, Japan. 8(2): 246-257.

10. Sidle R.C., Taylor D., Adger W.N., Lowe D.J., De Lange W.P., Newanham R.M., Lu X.X. \& Dodson J.R. (2004). Interactions of natural hazards and society in AustralAsia: evidence in past and recent records. Quaternary International 181-203.

11. Samarawickrama S.P. (2006). The tsunami hazard in Sri Lanka: strategic approach for the protection of lives, ecosystems and infrastructure. Coastal Engineering Journal, Special Issue, Indian Ocean Tsunami.

12. Samarawickrama S.P., Hettiarachchi S.S.L. \& Fernando H. (2006). Indian ocean tsunami on the Sri Lankan coast, near shore processes and the impact of coral removal The Second International Workshop on Coastal Disaster Prevention, Tsunami and Storm Surge Mitigation Tokyo, Japan.

13. Dias W.P.S., Dissanayake P.B.R. \& Chandrathilake R. (2006). Lessons learned from Tsunami damage in Sri Lanka, ICE Proceedings on Civil Engineering Vol. 159, No. 2, pp. 74-81.

14. Department of Census and Statistics (2005). Report on Post Tsunami recovery: Issues and challenges in Sri Lanka. Department of Census and Statistics, Maitland Crescent, Colombo 7.

15. Mallawaarachchi R.S., Jayasinghe M.T.R. \& Gunaratne M. (2007). Failure modes of buildings in Tsunami and cost effective preventive measures for future, International Conference on Mitigation of the Risk of Natural Hazards, $27^{\text {th }}-28^{\text {th }}$ March, University of Peradeniya, Peradeniya.

16. National Housing Development Authority, (2005). Tsunami disaster housing program, Guidelines for Housing Development in Coastal Sri Lanka, National Housing Development Authority, Sri Chittambalam A Gardiner Mawatha, Colombo 02.

17. Bhudaia P.D., Bhanderi P.D. \& Pindoria K. (2001). Repair and strengthen guide for earthquake damaged low rise domestic buildings in Gujarat, Gujarat Relief Engineering Advise Team (GREAT) publication, India.

18. Revenue Administration, Disaster Management and Mitigation Department (2005). Guidelines for reconstruction of houses affected by Tsunami in Tamil Nadu, Government of Tamil Nadu, India.

19. Department of Census and Statistics (2001). Report on Census of population and housing. Department of Census and Statistics, Maitland Crescent, Colombo 07.

20. Mallawaarachchi R.S. \& Jayasinghe C. (2007). Strategies for enhanced disaster resistance of commonly used building materials, International Conference on Mitigation of the Risk of Natural Hazards, $27^{\text {th }}-28^{\text {th }}$ March 2007, University of Peradeniya, Peradeniya. 